\title{
A influência das formações continuadas no cotidiano dos professores de Educação Física
}

The influence of continuing education in the everyday life of Physical Education teachers

\author{
Cláudia Pereira das Neves \\ Universidade Federal de Pelotas, Brasil
}

Vivian Hernandez Botelho

Universidade Federal de Pelotas, Brasil

Patrícia da Rosa Louzada da Silva

Universidade Federal de Pelotas, Brasil

Eraldo dos Santos Pinbeiro

Universidade Federal de Pelotas, Brasil

esppoa@gmail.com

\section{Resumo:}

O presente estudo teve como objetivo investigar a formação continuada, ofertada pela Secretaria Municipal de Educação (SMED) de Pelotas em parceria com a Escola Superior de Educação Física da Universidade Federal de Pelotas (ESEF/UFPel), como possibilidade de aprimoramento profissional de seus participantes. Trata-se de um estudo de natureza qualitativa, desenvolvido com quatro professores concursados de Educação Física da rede pública municipal de Pelotas, no Rio Grande do Sul, que atenderam ao critério de ter participado das formações continuadas de rugby, hóquei, punhobol e beisebol ofertadas pela SMED em parceria com ESEF/UFPel nos anos de 2017 e 2018. O instrumento utilizado para coleta das informações foi uma entrevista semiestruturada aplicada individualmente aos professores. Como principais resultados encontrados destacam-se a importância da formação continuada em relação ao conhecimento e aplicação de modalidades esportivas até então não convencionais nas escolas e a influência da formação no sentido de um estímulo à promoção e participação em festivais esportivos de cunho escolar. Portanto, através das formações, foi possível propiciar uma ressignificação do ensino do esporte no ambiente escolar, ao instigar o fomento de modalidades esportivas não convencionais, assim como a oferta de espaços para competição escolar.

PalaVras-ChaVE: Esportes, Escola, Percepção, Experiências.

\section{Abstract:}

This study aimed to investigate the continuing education offered by the Municipal Education Department (SMED) of Pelotas, in partnership with the Higher School of Physical Education of the Federal University of Pelotas (ESEF/UFPel), as a possibility of professional improvement of its participants. This is a qualitative study developed with four Physical Education teachers from public schools in Pelotas, in Rio Grande do Sul, which met the criteria of having participated in the continuous training courses of rugby, hockey, handball and baseball offered by SMED, in partnership with ESEF/UFPel, in 2017 and 2018. The instrument used to collect the information was a semi-structured interview applied individually to the teachers. The main results found include the importance of continuing education related with knowledge and application of sports that were hitherto unconventional in schools, and the influence of training in stimulating promotion and participation in school sports festivals. Therefore, through the training it was possible to provide a new meaning of teaching sports in the school environment, by promoting unconventional sports, as well as providing spaces for school competition.

KeYwords: Sports, Schools, Perception, Experiences. 


\section{INTRODUÇÃO}

A Educação Física escolar está em constante transformação, tendo passado por várias mudanças ao longo da história. No seu início, nos séculos XVIII e XIX, constituiu-se exclusivamente a partir de influências militares e da área médica. Posteriormente, suas características foram sendo modificadas, até que nos anos 50 e 60 do século XX passa a ter um foco mais educativo (Bracht, 1999, p.72; Steinhilber, 1996). Ademais, na transição entre a década de 70 e, principalmente, consolidando-se na de 80 , foram estabelecidos objetivos e princípios pedagógicos para a área da Educação Física, por meio do denominado movimento renovador, sendo adotado o conceito de cultura corporal (Brasil, 1997).

Com o advento dos Parâmetros Curriculares Nacionais (PCN), a Educação Física passa a considerar as características dos alunos e alunas e suas dimensões cognitiva, corporal, afetiva, ética, estética, de relação interpessoal e inserção cultural (Brasil, 1997, p.24). A Base Nacional Comum Curricular (BNCC) prescreve que a "Educação Física tem a responsabilidade de oferecer aos escolares vivências que sejam significativas e que envolvam as atividades de movimento corporal” (Brasil, 2017, p.213).

A Educação Física, na BNCC, apresenta-se como um componente curricular, sendo o esporte - o qual é subdivido em esportes de marca, invasão, combate, técnico combinatório, campo e taco, rede e parede - categorizado como uma das seis unidades temáticas previstas. Cabe destacar que o esporte é um fenômeno sociocultural da humanidade e, tratando-se do ambiente escolar, o esporte educacional, com caráter formativo, é o mais indicado (Tubino, 2002).

De acordo com Frizzo (2012), quanto à seleção dos conteúdos para as aulas de Educação Física, há uma hegemonia das modalidades futebol, voleibol, handebol e basquetebol. No entanto, é fundamental que a prática pedagógica da Educação Física seja a mais diversificada possível, ampliando-se para outras modalidades esportivas além dessas (Brasil, 2013).

Destaca-se que no campo da docência os professores passam a decidir o que é pertinente ao exercício de sua prática pedagógica, utilizam como base, muitas vezes, os conceitos compreendidos sobre conteúdos e modalidades do período de sua graduação. Um mecanismo propulsor para a diversificação das práticas na Educação Física escolar podem ser os espaços de trocas de experiências, ou seja, a formação continuada, a qual constitui importante meio de aproximação entre os educadores, além de promover diálogo com Instituições de ensino Universitário. "Nesse processo, os professores refletem e reformulam seus saberes, no sentido de construir um saber mais amplo, constituído por todos os outros e que será legitimado pela prática cotidiana” (Clates, Leães, Camargo \& Ivo, 2019).

No município de Pelotas, no Rio Grande do Sul, a SMED oferta, anualmente, cursos de formação para os professores da rede, em parceria com a ESEF/UFPEL, através do Laboratório de Estudos em Esporte Coletivo (LEECol). No ano de 2017 foram ofertadas seis formações continuadas, sendo os conteúdos de handebol, rugby, punhobol, hóquei, Educação Física para educação infantil e xadrez na escola. No seguinte ano, 2018, os temas foram: handebol, rugby, hóquei, punhobol, mini atletismo, iniciação esportiva e beisebol. Os temas e modalidades das propostas formativas são uma escolha em comum acordo entre SMED e ESEF/ UFPel que leva em consideração indicações dos professores da rede, em encontros passados, assim como a proposta dos formadores, que muitas vezes ofertam os temas de acordo com seus estudos de mestrado ou doutorado.

Para realização das formações a SMED organizava a comunicação com os professores, à liberação das escolas e o controle de presenças. Já o LEECol ficava encarregado de: preparar o material didático e as oficinas de 4 h de formação teórica/prática de cada uma das modalidades ${ }^{1}$, disponibilizar os materiais esportivos (kit) ${ }^{2}$ para que os professores utilizassem em suas aulas. Promover workshop de $2 \mathrm{~h}$ para sanar dúvidas após 15 dias de cada uma das oficinas e organizar festivais interescolares nas dependências da ESEF/UFPel. Além de avaliar o processo formativo de cada ano, em média as oficinas obtiveram 25 professores participantes. 
Nesse sentido, compreender a percepção dos professores que participaram das formações passa a ser de fundamental importância para a compreensão, reorganização e estruturação de um programa de formação continuada de longo prazo, principalmente em se tratando da ampliação cultural do esporte por meio de modalidades coletivas, ainda, pouco disseminadas na escola. Portanto, o objetivo deste estudo foi investigar a formação continuada ofertada pela SMED em parceria com o LEECol/ESEF/UFPEL, como possibilidade de aprimoramento profissional de seus participantes.

\section{Metodologia}

O presente estudo foi aprovado pelo Comitê de Ética em Pesquisa com Seres Humanos da Escola Superior de Educação Física da Universidade Federal de Pelotas (ESEF/UFPEL), sob o parecer de $\mathrm{n}^{\circ}$ 3.325.785. Para sua realização, primeiramente ocorreu o contato com a Secretária Municipal de Educação e Desporto (SMED), quando foi apresentada uma carta de intenções, apresentando a proposta, solicitação para a realização do estudo e da listagem dos professores participantes das formações continuadas do Município.

O estudo, de natureza qualitativa, do tipo descritivo, foi desenvolvido com professores concursados de Educação Física, da rede pública municipal de Pelotas, no Rio Grande do Sul participantes das formações continuadas ofertadas nos anos de 2017 e 2018. Para seleção dos participantes foi verificada a frequência nas listagens de chamada de cada uma das formações continuadas. Esses documentos de registro foram fornecidos pela SMED. Para compor esse estudo, buscou-se identificar cinco professores que possuísse 100\% de frequência ou igual ou maior que $80 \%$ ao longo de todos os encontros formativos. Caso fosse necessário, para se chegar ao número de cinco participantes, seria realizado um sorteio entre os mais frequentes. $\mathrm{O}$ que não foi necessário já que ao analisar as listagens de frequência percebeu-se uma grande rotatividade dos professores ao longo das formações continuadas ofertadas e apenas cinco atenderam ao critério de inclusão por frequência estabelecida.

$\mathrm{Na}$ fase de identificação e apresentação do estudo, quatro professores atenderam aos critérios de ter disponibilidade e autorizar a coleta das informações por meio dos cuidados éticos e um professor disse não poder participar do estudo. Com isso, o número de participantes do presente estudo foi o de quatro professores.

Como instrumento para a coleta das informações foi utilizada uma entrevista semiestruturada, com um roteiro de investigação estabelecido previamente, o qual questionava a formação continuada da SMED e a aplicação prática dos conteúdos estudados na atividade docente dos participantes. As entrevistas foram realizadas face a face, em local reservado, evitando o máximo de interferências externas. Todas as entrevistas foram gravadas em áudio, com recurso do aparelho "Motor G5s", a partir do consentimento dos participantes. Logo após, foram transcritas e, a seguir, entregues para a leitura e validação do conteúdo pelos entrevistados, garantindo assim o máximo de fidedignidade ao estudo.

A análise das informações ocorreu por análise de conteúdo, conforme sugere a técnica de Bardin, na busca de descrever o conteúdo emitido no processo de comunicação (Bardin, 2009). Os procedimentos da análise de conteúdo foram, primeiramente, uma leitura ampla e flutuante do texto, processo denominado de préanálise, seguido de uma exploração detalhada do texto, classificando e compilando por semelhanças de sentido as evidências encontradas, buscando responder à questão investigativa do estudo e finalizado pela codificação de duas categorias e consecutivas interpretações com base na teoria (Bardin, 2009).

\section{Resultados e discussão}

Para preservar a identidade dos participantes, os mesmos serão referenciados por Participante, seguidos de números de um a quatro. Os principais achados do estudo são referentes às categorias "A importância 
da formação continuada em relação ao conhecimento e à aplicação de modalidades esportivas não convencionais na escola", a qual foi definida a priori, e a "Promoção e participação em festivais esportivos, assim como percepção dos benefícios educacionais da competição para os escolares”, a qual emergiu ao longo da análise.

- A importância da formação continuada em relação ao conhecimento e à aplicação de modalidades esportivas não convencionais na escola

Ao serem questionados sobre as principais contribuições da formação continuada para o aprimoramento profissional, foi possível identificar que os participantes reconheceram benefícios com relação ao trabalho docente e o aumento de seus conhecimentos esportivos.

Os participantes relatam ser as seguintes as principais contribuições da formação continuada:
Apresentar e trazer uma gama maior de conteúdos pra gente não ficar sempre limitados nas modalidades tradicionais (Participante 4);
Trazer conhecimento, a parte de reciclar, a troca de experiências que a gente teve com os colegas, [...], até pra estimular a gente como professor (Participante 3);
[...] contribuiu pra prática, pra motivar os alunos, hoje tu já vê uma coisa diferente, uma forma diferente de trabalhar aquele conteúdo (Participante1).

Segundo Ilha, Afonso, Da Silva, Santos \& Montiel (2019), "[a] formação continuada de professores, sem dúvidas, tem um papel importante quando pensamos sobre a responsabilidade social das universidades", porque aproxima as discussões teóricas do ambiente escolar, sendo a formação continuada um momento importante em que o sujeito tem a possibilidade de repensar as ações pedagógicas e rever, atualizar os conteúdos de sua graduação. $\mathrm{O}$ Participante 1 refere-se às formações como momentos de agregar outras metodologias de ensino e estratégias para contribuir com o aprendizado dos escolares. Assim, explorar novos caminhos na formação continuada expressa a necessidade de uma nova leitura do mundo, em que a teoria e a prática estejam articuladas, a fim de que esse conhecimento tenha impacto nas aulas, colaborando com o aprendizado dos escolares (Silva \& Nascimento, 2012).

A qualidade da formação continuada é um fator importante para que ocorra a ressignificação do conteúdo esporte no ambiente escolar e para que, de fato, chegue até o público final, que são os alunos e alunas. Reforça-se que há forte influência de conteúdos esportivos convencionais como futsal, voleibol, basquetebol e handebol no contexto das aulas de Educação Física (Oliveira \& Frizzo, 2019). A participação dos professores, assim como a vontade de promover em suas aulas uma prática pedagógica diferenciada também são fatores significativos. A seguir é apresentado um recorte da entrevista do Participante 3, quando o mesmo justamente aponta indícios de que a formação continuada experienciada foi capaz de motivá-lo a tentar o novo.

Motiva pra gente trabalhar e pesquisar, em buscar algo novo, mudou totalmente meu modo de ensinar. Eu era muito técnico, muito esporte de regras, treino de fundamentos e aquela formação trouxe outra visão pra gente, pode ser mais lúdico e prazeroso o modo de ensinar (Participante3).

Achados como esse também são encontrados na literatura. Uma pesquisa sobre uma formação continuada em atletismo para professores de Educação Física da rede municipal de Goiânia indicou resultados positivos, no sentido de ter sido relevante aos participantes, justamente pelos momentos de troca de experiência, oportunidade de construção coletiva de conhecimento, discussão e reflexão da prática pedagógica entre os professores (Gemente \& Matthiesen, 2017).

Ademais, ao serem questionados sobre o conhecimento dos conteúdos e modalidades ofertados no presente ciclo de formações continuadas, os participantes do presente estudo assim se manifestaram:

Não, não conhecia nenhuma das modalidades (Participante 1);

[...] a gente conhecia mais de televisão, mas não tinha prática, não tinha nem a questão de regras [...] eu não tinha quase nenhum conhecimento (Participante 2 );

Eu não conhecia o Rugby e nem o Punhobol (Participante 3); 
Eu conhecia só de nome, eu não sabia jogar, não sabia regras, nada (Participante 4).

Dessa forma, percebe-se que, para esses professores, a referida formação continuada influenciou de modo favorável, na medida em que promoveu uma atualização esportiva, além de ampliar o conhecimento sobre outras modalidades esportivas para além das convencionais, porque ao serem questionados sobre as modalidades com maior frequência em suas aulas os quatro participantes indicaram a presença das modalidades convencionais voleibol, basquetebol, handebol e futebol/futsal. Sabe-se que a formação profissional é um processo contínuo que perpassa a formação inicial e se estende através da formação continuada, uma vez que constantemente a prática exige reflexão e a busca por novas estratégias de ensino (Rossi \& Hunger, 2012; Santos, 2014).

Para além de investigar a ampliação cultural sobre as modalidades, os professores foram questionados também sobre a inserção das mesmas em suas aulas. De modo geral, relataram conseguir aplicar todas as modalidades promovidas nas formações continuadas aqui estudadas. No entanto, em trechos de suas entrevistas, há destaque para o punhobol e o rugby, sem que os conteúdos de beisebol ou hóquei fossem citados.

Os professores afirmam que as formações continuadas contribuíram de forma significativa no processo de criação de condições para transmitir novos conhecimentos aos escolares, já que os participantes declararam trabalhar com esporte, especificamente com handebol, vôlei, basquete, futsal, atletismo, futebol, xadrez, câmbio e lutas. No entanto, apontando mudanças que ocorreram após suas participações nas formações continuadas promovidas pela SMED e UFPel. Como exemplo, os participantes dizem ter revisto a forma como estavam ministrando os conteúdos em suas aulas, sendo influenciados pelas formações, aqui estudadas, observando que era necessário desenvolver aspectos motores comuns ao esporte, mas também atitudinais, na tentativa de inclusão a todos, conforme é evidenciado no trecho a seguir:

[...] A gente não ensina só esporte, a gente ensina a questão da autonomia, do movimento, de trabalhar as capacidades dele, [...] a gente tá querendo desenvolver ele como um todo. [...] acho que isso daí vem um pouco também em direção dos cursos, pra desenvolver o aluno com iniciativas novas que incluam mais, como no Rugby, que foi um esporte que me foi apresentado como atividade que dá para incluir crianças com diferentes capacidades e tipos físicos onde cada um consegue contribuir ao seu modo (Participante 1).

Quando questionados sobre quais obstáculos foram enfrentados ao implementar as modalidades em suas aulas, o principal problema apontado foi espaço físico. Uma crítica à formação continuada foi o fato de que durante os encontros formativos as modalidades foram apresentadas em local apropriado para a prática, porém, quando o professor vai aplicar na escola, a realidade não é a mesma e isso torna-se uma barreira para a prática pedagógica.

Às vezes não ter o material, porque, por exemplo, hóquei de grama e beisebol, a gente não tem material e não tendo material fica um pouco mais difícil, a maioria das modalidades a secretaria conseguiu material e isso facilitou [...] (Participante 4).

Além disso, uma outra colocação dos participantes referente à dificuldade de inserção das modalidades durante o período letivo, foi devido à carga horária restrita que têm para abordar uma grande variedade de conteúdos. Julga-se que haverá desafios para a implementação de uma prática pedagógica com maior diversidade, no entanto, cabe ao professor e sua coordenação pedagógica estruturar um plano que contemple amplamente todas as demandas do componente curricular Educação Física.

As formações foram uma forma de conhecer outras possibilidades para desenvolver os escolares, em que houvesse a inclusão de todos os alunos e alunas, sem exceção, pra desenvolver o aluno com iniciativas novas, que incluam mais (Participante 1).

A partir de constatações como essa, ressalta-se a importância da organização e estrutura de um plano de ensino que venha atender a BNCC, já que a mesma prevê o esporte categorizado em diversas unidades temáticas. O punhobol, por exemplo, atenderia à indicação de esporte de rede, já o beisebol e o hóquei atenderiam ao esporte de campo e taco, enquanto o rugby contemplaria o esporte de invasão. O Participante 
4 expõe em sua fala como aplica, na prática, de maneira pedagógica e progressiva, os esportes de rede para atingir seus objetivos.

[...] a gente conseguiu inserir e nos planejamentos, sim, porque, por exemplo, a organização pra introduzir o vôlei eu já tinha diferente, agora eu trabalho os esportes de rede divisória e começo com câmbio, passo por punhobol, pra entrar no vôlei (Participante 4).

Em se tratando de espaços e materiais, é um direito do professor ter espaços e condições para sua prática pedagógica, mas a realidade de muitas escolas brasileiras é precária, nem todos têm uma quadra poliesportiva ou espaços adequados.

Tenho na minha escola uma quadra poliesportiva, não que a gente vá fazer as coisas só tendo espaço adequado, a gente pode improvisar, mas eu acho que é importante o aluno ter uma estrutura adequada à disposição, para se motivar. Eu tenho uma estrutura adequada, dá pra trabalhar praticamente tudo que se propõe, assim, com uma certa qualidade e ainda assim o espaço é insuficiente, tem que dividir o espaço às vezes. Não sou só eu que uso o espaço[...] (Participante1).

Compreende-se que os obstáculos da prática pedagógica escolar irão sempre existir e, muitas vezes, impossibilitar o desenvolvimento efetivo da proposta de ensino (Santos \& Nista-Piccolo, 2011). No entanto, discorda-se de que essa seja a justificativa para não propor uma prática diversificada nas aulas de Educação Física. As condições de trabalho não deveriam impedir que o conhecimento adquirido nas formações continuadas fosse efetivado, praticado e tornado aprendizado dos alunos e alunas. Julga-se que, pelo contrário, a partir da ampliação cultural, de apropriarem-se de novas possibilidades de ensino, a justificativa e criação de um cenário de indignação entre os professores pode vir a motivá-los a buscar melhores condições de trabalho.

Ademais, quando os participantes foram questionados sobre como a formação continuada de que haviam participado contribuiu para os planejamentos de ensino, dois professores relataram ter implantado as modalidades em seus planos anuais, enquanto os outros dois disseram ter trabalhado com as modalidades, mas não tê-las acrescentado em seu planejamento anual.

Nessa categoria, denominada a importância da formação continuada em relação ao conhecimento e aplicação de modalidades esportivas não tradicionais na escola, discutiu-se o quanto a formação continuada estudada surtiu efeito sobre as práticas pedagógicas dos professores, assim como indicaram-se os motivos alegados quando os mesmos disseram não terem aplicado aqueles conteúdos. Além disso, a realização da presente formação continuada e o conhecimento de modalidades esportivas até então pouco conhecidas proporcionou que os participantes estabelecessem outras formas de aplicá-las no ambiente escolar, as quais serão discutidas na categoria a seguir.

- Promoção e participação em festivais esportivos, assim como percepção dos benefícios educacionais da competição para os escolares

A partir da análise das entrevistas, foi possível detectar a recorrente indicação de que os professores promoveram a participação de seus alunos e alunas em festivais esportivos de modalidades não tradicionais, ou seja, indicando o emprego das modalidades discutidas na formação continuada estudada. Assim, a mesma será tratada como categoria emergente e discutida a partir da teoria.

A competição é elemento fundamental do esporte, conferindo sentido a sua existência; é nela que o esporte se manifesta em sua totalidade (Faria, Caregnato \& Cavichiolli, 2019). Os professores citaram a importância da participação dos escolares em competições e festivais dentro e fora da escola, desenvolvendo as competências do ato de competir, como vencer, perder e aprender que todos podem participar, independente das características físicas de cada um.

Autores como Scaglia, Medeiros e Sadi (2006) enfatizam que ensinar esporte também é ensinar a competir. Porém, a competição não resulta necessariamente que o vencedor é melhor que o perdedor, mas importa, sobretudo, o que podemos compreender através das diferentes situações de vencer e ser vencido (Balbino, 
Galatti, Ferreira \& Paes, 2013). Os autores destacam que esse elemento tão importante no esporte também faz parte dos mais diversos cenários da vida, nas relações pessoais, e o ambiente da Educação Física escolar pode auxiliar nesse processo.

A concorrência e a competição são o que move o desporto e a vida, desse modo, não podemos negálas, porém, aqui os professores pressupõem seu compromisso com a educabilidade (Bento, 2006, p.14). Apresentamos como exemplo a experiência do Participante 2, ao proporcionar a participação de seus escolares em um festival.

[...] levei um grupo dos meus alunos no festival de Punhobol que teve aqui na ESEF, e só alia a vivência de tirar eles da escola e aqui estar junto de outras escolas e passar aqui a tarde já é! Isso é o que vale mais, porque o resultado, a performance pra mim isso eu nunca trabalhei, eu trabalho a questão deles terem a aula prática e ali teve a questão de oportunizar eles a sair um pouco do ambiente escolar e levar eles assim pra esses outros ambientes onde tenha Educação Física que possa ser trabalhada, onde tenha um espaço melhor e ver e ter essa troca de ideias e troca com alunos de outras escolas (Participante 2).

$\mathrm{Na}$ fala do Participante 2, pode-se observar a importância dada à possibilidade de seus alunos e alunas participarem de uma competição, visto que estariam em contato com pessoas além do ambiente da escola, ou seja, ele fez da competição uma possibilidade de interação, conforme já afirmavam Reverdito, Scaglia e Montagner (2013), que a competição e o esporte são o que fazemos deles. Como há diversos sentimentos envolvidos no ato de competir, é necessário aprender a conviver com eles, principalmente com a aceitação de perder ou vencer, reações essas que somente ao serem vivenciadas podem ser, de fato, compreendidas. Sendo assim, Faria, Caregnato e Cavichiolli (2019) sugerem que ensinando a ganhar - fator esse mais almejado pelos escolares -, também se está ensinando a perder, desde que a conquista esteja baseada num ato de humildade, tendo-se presente que as vitórias são reflexos de um jogo coletivo, com uma equipe bem estruturada, que respeita os limites dos colegas e que o resultado é devido a superação, desempenho e disciplina.

Com relação ao festival anteriormente citado pelo Participante 2, destaca-se sua íntima relação com a formação continuada estudada, uma vez que faz parte da própria programação da formação, enquanto uma das estratégias utilizadas para estimular a aplicação dos conteúdos ministrados pelos professores em suas escolas. Assim, anualmente, a ESEF, juntamente com a SMED, realiza os festivais escolares, como um recurso pedagógico com objetivo educativo, na tentativa de envolver professores, alunos e alunas. No período que compreende a investigação deste estudo, foram ofertados cinco festivais de três modalidades - rugby, punhobol e hóquei. A partir das entrevistas, dois participantes mencionaram suas experiências nos festivais em que participaram.

De acordo com a análise das entrevistas, identificou-se a realização de outras atividades no ambiente escolar, as quais surgiram após a participação nas formações. Salienta-se que as atividades nem sempre envolveram as modalidades aprendidas, mas percebe-se a relação de mobilização gerada a partir da formação continuada. Por meio das evidências encontradas, pôde-se identificar que a formação estudada impulsionou uma maior motivação dos professores para realizar outras atividades, como a participação nos jogos escolares de Pelotas, reativação do projeto de handebol na escola e inserção do rugby na gincana escolar.

Percebe-se que os professores participantes passaram a ter uma maior reflexão e percepção de aspectos positivos na ação de competir, assim como os ganhos na formação pessoal dos escolares envolvidos. $\mathrm{O}$ achado é corroborado pelo trecho do estudo de Montiel, Afonso, Dos Santos \& Da Silva (2019) ao apontar que os participantes percebiam de forma positiva a competição, indicando suas possibilidades de estimular o diálogo e os acordos no ambiente escolar. Na maioria das vezes, essa competição é guiada pela mediação do professor, que é o principal mediador no processo de aprendizagem de seus alunos e alunas durante as competições esportivas (Sadi, 2013).

A partir dos achados, nota-se que a formação continuada estudada influenciou na rotina escolar, oportunizando outras práticas aos escolares e a valorização dessas vivências, conforme menção do Participante 1. 
[...] a gente começa a resgatar as práticas e se motivar a fazer alguma coisa. O que importa é que eu estou levando eles pra jogar, se eles vencerem, venceram, se eles não venceram eu tento buscar sempre o lado bom da experiência (Participante 1).

Nesse sentido, é notória a contribuição da formação continuada aqui averiguada, que não só promoveu o conhecimento de modalidades esportivas pouco convencionais, como impulsionou outras ações. Os professores sentiram-se motivados para propor outras práticas a seus escolares, concorrendo para o aprendizado integral.

\section{CONSIDERAÇÕES FINAIS}

Como resultado da investigação sobre a formação continuada como possibilidade de aprimoramento profissional de seus participantes, considera-se que os resultados da parceria entre a Universidade e a Prefeitura, por meio da SMED, foram positivos. Foi possível propiciar uma ressignificação do ensino do esporte no ambiente escolar, ao instigar o fomento de modalidades esportivas não convencionais, assim como a oferta de espaços para competição escolar.

Aponta-se, como limitação do estudo, o não acompanhamento individualizado desses professores ao longo de cada formação. Sugere-se, por exemplo, a escrita de narrativas ou questionários autoaplicáveis, para que os participantes possam expor suas percepções e contribuir, ainda mais, com a estrutura e organização das próximas formações continuadas. Ademais, refletir sobre a formação continuada e a manutenção de espaços de troca entre a universidade e a comunidade é de suma importância para a formação profissional e pessoal dos professores de Educação Física.

\section{REFERÊNCIAS}

Balbino, H. F., Galatti, L. R., Ferreira, H. B. \& Paes, R. R. (2013). Pedagogia do Esporte: significações da iniciação esportiva e da competição. In: Reverdito, R. S., Scaglia, A. J. \& Montagner, P. C. Pedagogia do esporte: aspectos conceituais da competição e estudos aplicados (pp. 41-68). São Paulo: Phorte.

Bardin, L. (2009). Análise de Conteúdo. Lisboa: Edições 70.

Bento, J. O. (2006). Pedagogia do desporte definições, conceitos e orientaçôes. In: Tani, G., Bento, J. O. \& Petersen, R. D. S.(Orgs.). Pedagogia do Desporto. Rio de Janeiro/Guanabara: Koogan.

Bracht, V. (1999). A constituição das teorias pedagógicas da educação física. Cadernos Cedes, 19(48), 69-88. Disponível em: http://www.scielo.br/scielo.php?pid=S0101-32621999000100005\&script=sci_arttext. Acesso em: 24 abr. 2020.

Brasil (1997). Secretaria de Educação Fundamental. Parâmetros curriculares nacionais: introdução aos parâmetros curriculares nacionais. Brasília: MEC/SEF.

Brasil (2013). Diagnóstico Nacional do Esporte. Brasilia: Ministério do Esporte. Disponível em: http://arquivo.esport e.gov.br/diesporte/2.html. Acesso em: 24 abr. 2020.

Brasil (2017). Ministério da Educação. Secretaria de Educação Básica. Base Nacional Comum Curricular: educação é a base. Disponível em: http://portal.mec.gov.br/conselho-nacional-de-educacao/base-nacional-comum-curricu lar-bncc. Acesso em: 27 abr. 2020.

Clates, D., Leães, C., Camargo, M. C. \& Ivo, A. (2019). Socialização docente e experiências pré-profissionais. Educación Fisica Y Ciencia, 21(3). https://doi.org/10.24215/23142561e094

Faria, F., Caregnato, A. F. \& Cavichiolli, F. R. (2019). O esporte e a competição na educação física escolar: perspectivas educacionais a partir dos conceitos da pedagogia do esporte. Kinesis, 37, 01-16. Disponível em: https://periodi cos.ufsm.br/kinesis/article/view/22863. Acesso em: 24 abr. 2020.

Frizzo, G. F. E. (2012). A organização do trabalhopedagógico da Educação Física na escola capitalista. (Tese de doutorado em Ciências do Movimento Humano) - Escola de Educação Física, Universidade Federal do Rio Grande do Sul, UFRGS, Porto Alegre. 
Gemente, F. R. F. \& Matthiesen, S. Q. (2017). Formação continuada de professores: construindo possibilidades para o ensino do atletismo na Educação Física escolar. Educar em Revista, 65, 183-200. Disponível em: https://revis tas.ufpr.br/educar/article/view/49226. Acesso em: 24 abr. 2020.

Oliveira, I. \& Frizzo, G. (2019). A organização do trabalho pedagógico da Educação Física e a carreira docente. Educación Física Y Ciencia, 21(1). https://doi.org/10.24215/23142561e068.

Ilha, F. R. S., Afonso, M. R., Da Silva, P. R. L., Santos, L. L. \& Montiel, F. C. (2019). Interfaces entre pesquisa e extensão: uma proposta de ressignificação da formação em educação física escolar. Caderno de Educação Física e Esporte, 17(1), 273-280. Disponível em: http://e-revista.unioeste.br/index.php/cadernoedfisica/article/view/2 1971. Acesso em: 24 abr. 2020.

Montiel, F. C., Afonso, M. R., Dos Santos, L. L. \& Da Silva, P. R. L. (2019). Ética, autonomia e pensamento crítico nas aulas de Educação Física no ensino médio. Motrivivência, Florianópolis, 31(58), 01-21. Disponível em: https:// periodicos.ufsc.br/index.php/motrivivencia/article/view/2175-8042.2019e56991. Acesso em: 24 abr. 2020.

Reverdito, R. S., Scaglia, A. J. \& Montagner, P. C. (2013). Pedagogia do esporte: aspectos conceituais da competição e estudos aplicados. São Paulo: Phorte.

Rossi, F. \& Hunger, D. (2012). As etapas da carreira docente e o processo de formação continuada de professores de Educação Física. Revista Brasileira de Educação Física e Esporte, 26(2), 323-328. Disponível em: http://www.sci elo.br/scielo.php?script=sci_arttext\&pid=S1807-55092012000200014. Acesso em: 24 abr. 2020.

Silva, M. C. \& Nascimento, J. V. (2012). Estruturação da Educação Física no Ensino Médio e Técnico do Centro Federal de Educação Tecnológica de Santa Catarina. In: Folle, A. \& Farias, G. O. Educação Física: prática pedagógica e trabalho docente. (pp. 27-49). Florianópolis: Editora da UDESC.

Santos, R. S. A. (2014). A dança como conteúdo das aulas de educação física: suas possibilidades a partir da formação continuada dos professores do municipio de Bagé/RS. (Dissertação de mestrado em Educação Física) - Escola Superior de Educação Física, Universidade Federal de Pelotas, Pelotas.

Santos, M. A. G. N. \& Nista-Piccolo, V. L. (2011). Esporte e o ensino médio: a visão dos professores de educação física da rede pública. Revista Brasileira de Educação Física e Esporte, 25, 65-78. Disponível em: http://www.scielo.b r/pdf/rbefe/v25n1/08.pdf. Acesso em: 24 abr. 2020.

Sadi, R. S. (2013). Educação Física e Competição: crença no esporte educacional/escolar? In: Reverdito, R. S., Scaglia, A. J. \& Montagner, P. C. Pedagogia do esporte: aspectos conceituais da competição e estudos aplicados. (pp. 99-122). São Paulo: Phorte.

Scaglia, A. J., Medeiros, M. \& Sadi, R. S. (2006). Competições Pedagógicas e Festivais Esportivos: questões pertinentes ao treinamento esportivo. Revista Virtual EFArtigos, 3(23).Disponível em: http://efartigos.atspace.org/esporte s/artigo68.html. Acesso em: 24 abr. 2020.

Steinhilber, J. (1996). Profissional de Educação Física existe? Rio de Janeiro/RJ: Sprint.

Tubino, M. J. G. (2002). Uma Visão Paradigmática das Perspectivas do Esporte para o Início do Século XXI. In: Gebara, A. [et al.] \& Moreira, W. W. (Org.). Educação fisica \& esportes: Perspectivas para o século XXI. 9. ed. (pp.125-139). Campinas: Papirus.

\section{Notas}

1 As oficinas foram orientadas por professores com ampla experiência e formação nas modalidades oferecidas.inclus

2 Kit rugby ( 1 bola e 10 cintos de tag rugby); kit hóquei ( 10 tacos e 5 bolas); kit punhobol ( 1 bola e um elástico/rede). No caso do beisebol, ensinou-se como utilizar material alternativo. 